\title{
Field Programmable Gate Array Based RF-THI Pulse Width Modulation Control for Three Phase Nverter Using Matlab Modelsim Cosimulation
}

\author{
${ }^{1}$ Valantina Stephen, ${ }^{1}$ L. Padma Suresh and ${ }^{2}$ P. Muthukumar \\ ${ }^{1}$ Department of Electrical and Electronics Engineering, \\ Noorul Islam Centre for Higher Education, Kumaracoil-629180, Thuckalay, TamilNadu, India \\ ${ }^{2}$ Department of Electrical and Electronics Engineering, \\ S. Veerasamy Chettiar College of Engineering and Technology, \\ Puliangudi-627855, Tirunelveli District, TamilNadu, India
}

Received 2012-07-30, Revised 2012-08-31; Accepted 2012-09-01

\begin{abstract}
This study proposes different configurations of PWM techniques for harmonic reduction and improvement of fundamental peak voltage. For providing adjustable frequency power to industrial applications, three-phase inverter is preferred. The general aim of this study is to reduce the third order harmonics and improve the Harmonic Spread Factor by different PWM techniques using matlab modelsim cosimulation. The gating signals to the inverter are produced by means of SPWM, RFPWM, Third Harmonic Injection (THI) and Hybrid Random Frequency THIPWM. FPGA because of its suitability in time critical systems it is used to produce gating signals to the switches in a three-phase bridge inverter. This study will provide the insight of trends and technologies of Third Order Harmonic Elimination and improvement of HSF using different PWM techniques. In addition, a performance comparison of proposed methods with modified PWM methods is also provided. The result of the proposed work shows that there is improvement in fundamental voltage, THD, HSF when a combination of RF-THI PWM techniques is used.
\end{abstract}

Keywords: Field Programmable Gate Array (FPGA), Inverter, Sinusoidal-PWM (SPWM), Random Frequency-PWM (RFPWM), Third Harmonic Injection (THI)

\section{INTRODUCTION}

Power Electronics is a fastest growing area in electrical machinery where the technology is associated with the adroit conversion control and conditioning of the electric power by static means from its available input form into the electrical output form in a desired manner. In the present scenario, inverters are commonly used for speed control of induction motors (Younis et al., 2002; MecoGutierrez et al., 2008). The main aim of Pulse Width Modulation (PWM) technique in an inverter is to shape the output voltage/output current spectra in a way to eliminate lower order harmonics. The fundamental component, Total Harmonic Distortion (THD) and Harmonic Spread Factor (HSF) can be controlled by different types of control techniques like SPWM, RFPWM, THIPWM and Hybrid Random Frequency carrier THI-PWM. Each of the above methods possesses different patterns of pulse width modulation and harmonic components (Boost and Ziogas, 1988; Holtz, 1992). Although sinusoidal pulse width modulation has many advantages, its foremost disadvantage is the limitation of fundamental magnitude which can be overcome through over modulation by increasing duty cycle (Kerkman et al., 1996). But when this method is operated beyond a particular modulator voltage it introduces lower order harmonics. In order to minimise unwanted harmonic content, i.e., a THD, a number of PWM techniques have been developed to reduce THD, HSF and switching losses (Jeevananthan et al., 2005). Since a three-phase bridge inverter provides adjustable frequency power than any other type of inverters it is preferred for industrial applications. In power electronics, various Pulse Width Modulation (PWM) techniques are widely employed to control the output of inverters. The gating signals to the inverter are produced by means of SPWM, RFPWM, THIPWM and Hybrid Random Frequency carrier THI-PWM techniques. The Corresponding Author: Valantina Stephen, Department of Electrical and Electronics Engineering, Noorul Islam Centre for Higher Education, Kumaracoil-629180, Thuckalay, Tamilnadu, India 
Field Programmable Gate Array is used to produce the gating signals.

The main advantage of digital controllers over the analog controllers is the switching frequency. With the usage of conventional analog controllers, for high switching frequencies in the range of kilohertz, switching loses will be predominant and hence the efficiency of the inverter circuitry becomes poor. That is why, to overcome this situation, soft switching techniques are introduced. With successively improving reliability and performance of microprocessors, digital control techniques have predominated over their analog counterparts in the past decade (Patel et al., 2009). Microprocessor based control schemes have the advantages of flexibility, higher reliability and lower cost. However, the demanding requirements of modern power conditioning systems have imposed tremendous computation load on the microprocessors. Therefore, the designers turn to the technology of Field Programmable Gate Array (FPGA) and hope that the high-speed hard-wired logic can enhance the computation capability of the digital controllers. The nonlinear dependence of the desired duty factor on the input and output voltages of the inverter can be easily taken into account in the software programming. This is not possible with analog controllers. As a much faster speed of operation than that of a DSP type digital controller is required, a Field Programmable Gate Array (FPGA) controller is selected. The FPGA-based digital controller has the advantage of a well-designed hardware, which has higher computation speed and short period of time for prototyping (Chang et al., 1997).

The main purpose of this study is to propose a novel control scheme which offers an improved performance when comparison to the existing methods in terms of fundamental Injection PWM (RF-THIPWM) is developed to give an improved fundamental inverter output waveform and to reduce the THD and HSF.

\subsection{Literature Review}

In recent years many new methods have been implemented for reduction of harmonics using different techniques of pulse width modulation. Enjeti et al. (1990) have proposed programmed PWM techniques to eliminate harmonics in order to improve the high voltage output spectra. Chen and Cheng (1999) developed an analogbased modified PWM scheme by which the lower order harmonic components were eliminated. In 2002 Andrzej M. Trzynadlowski and Zhiqiang Wang made a comparative study of many PWM schemes and found out RFPWM technique to be more effective. Jeevananthan et al. (2005) introduced a novel modified carrier PWM strategy for single phase full bridge inverter for improving THD and to achieve overmodulated fundamental voltage in 2005. Farid and Amar (2009) proposed a study on new controlled PWM inverters to highlight the features of controlled SVPWM. Mahesh, Ankit, Daval, Ketul in 2009 have developed a modified SPWM technique to limit the current and voltage harmonics and comparison is carried out with all PWM techniques. Deepthi and Saxena (2011) projected that in the case of a multilevel inverter with a resistive load; SPWM method provides the lowest total harmonic distortion.

\section{MATERIALS AND METHODS}

\subsection{Overview of the Methods Adapted}

Sine Pulse Width Modulation (SPWM): The modulating techniques which are very commonly used are the carrierbased technique (e.g., Sinusoidal Pulse Width Modulation, Random Frequency Pulse Width Modulation), the spacevector technique and the Selective-Harmonic-Elimination (SHE) technique. These techniques are used to control the amount of time required to switch the power valves on and off. SPWM technique is used only when the amplitude of the output voltage has to be greatly improved.

In the sinusoidal pulse width modulation technique as shown in Fig. 1, a high frequency triangular carrier wave, Vc is compared with a sinusoidal reference wave $\mathrm{Vr}$ of the desired frequency. The intersection of $\mathrm{Vc}$ and $\mathrm{Vr}$ waves determines the switching instants and the commutation of the modulated pulse. The carrier and the reference waves are mixed in a comparator. When the magnitude of the sinusoidal wave is higher than the triangular wave the comparator output is high, otherwise it is low. The comparator output is processed in a trigger pulse generator in such a manner that the output voltage wave of the inverter has a pulse width in agreement with the comparator output pulse width. The ratio of $\mathrm{Vr} / \mathrm{Vc}$ is called the Modulation Index (MI) and it controls the harmonic content of the output voltage waveform. In the proposed configuration, modulation index (ratio of peak value of the reference wave to peak value of the carrier wave) is varied in the range 0.2-1.2.

Out of the various modulation modes available, Sinusoidal PWM (SPWM) has been commonly used today. The major problem encountered in the above method is the larger harmonic content (Kawamura et al., 1988).

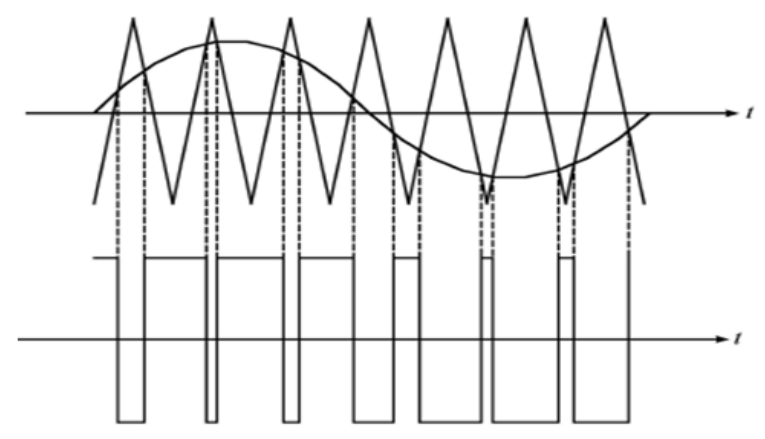

Fig. 1. Illustrating the SPWM switching pattern 


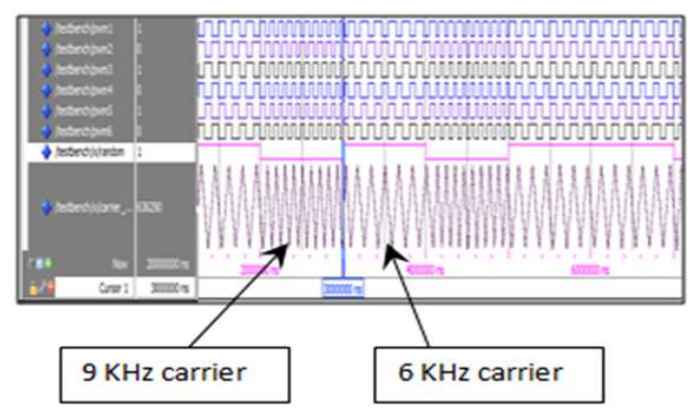

Fig. 2. Switching pattern for RFPWM technique

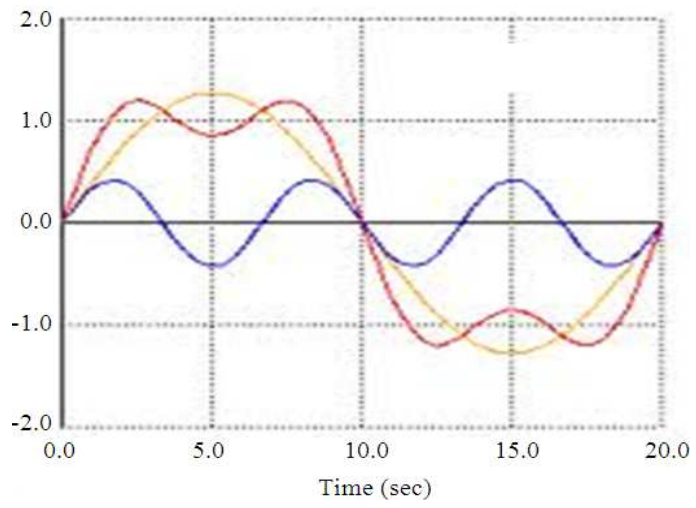

Fig. 3. Modulating signal for THI-PWM

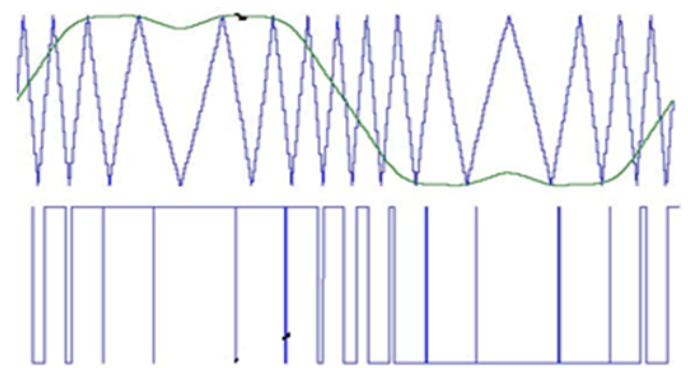

Fig. 4. Proposed Hybrid RF-THIPWM

\subsection{Random Frequency Pulse Width Modulation (RFPWM)}

In power electronic systems, pulse width modulation techniques operate at a fixed switching carrier frequency which produces unwanted effects as well as harmonic spikes. The significant importance of a power electronic system employing RFPWM is that its output harmonics are dispersed and distributed. This popular scheme can be achieved by many ways such as varying the switching number in a cycle, the carrier frequency or the slope of the triangular wave (Hussin et al., 2010).
In the proposed method as shown in Fig. 2, a randomly chosen carrier frequency signal with the help of random generator is used instead of a fixed carrier frequency as in the case of SPWM to perform the PWM switching scheme. It is preferred for high switching frequencies, owing to its simple architecture. However if the modulation index is low then the performance of the power electronic system will greatly degrade (Farid and Amar, 2009).

\subsection{Third Harmonic Injection (THI-PWM)}

Many techniques were developed for harmonic elimination especially for suppressing the lower order harmonics. The Third Harmonic Injection PWM (THIPWM) shown in Fig. 3 is a modification over the SPWM Technique wherein a suitable amount of third harmonic signal is added to the sinusoidal modulating signal of fundamental frequency (Deepthi and Saxena, 2011).

Then the resultant waveform (modified modulating waveform) is compared with the high frequency triangular carrier waveform. The comparator output is used for controlling the inverter switches exactly as in SPWM inverter. In other words, if a fundamental frequency signal having peak magnitude slightly higher than the peak magnitude of the carrier signal, is mixed with suitable amount of 3rd harmonic it may result in a modified signal of peak magnitude not exceeding that of the carrier signal which is suitable for three phase inverters. Thus the peak of the modulating signal remains lower than the peak of carrier signal and still the fundamental component of output voltage has a magnitude higher than what a SPWM can output by varying the modulation index. The maximum amplitude of fundamental in the reference and in the output voltages can be increased by the addition of third harmonic signal (Huo and Trzynadlowski, 1999). In the proposed Hybrid RF-THIPWM scheme, the combination of the above two methods are used as shown in Fig. 4.

\subsection{Generation of Pulses Using FPGA: Sine Wave Generation}

The first and foremost aspect in generating sine PWM is to generate voltage-controlled oscillations. As the entire process is in digital format, it is not possible to generate the conventional analog sine wave. Further, this sine wave serves as a reference signal for comparison. Hence, if we know the values of the voltage controlled oscillations at any instant, then the purpose could be served. In this scheme, the controlled sinusoidal oscillations are generated in the form of a look up table and the amplitude control block controls the voltage magnitude. The regular sampling has certain advantages when implemented using digital techniques (Green et al., 1992). The block diagram of hardware prototype is shown in Fig. 5. 


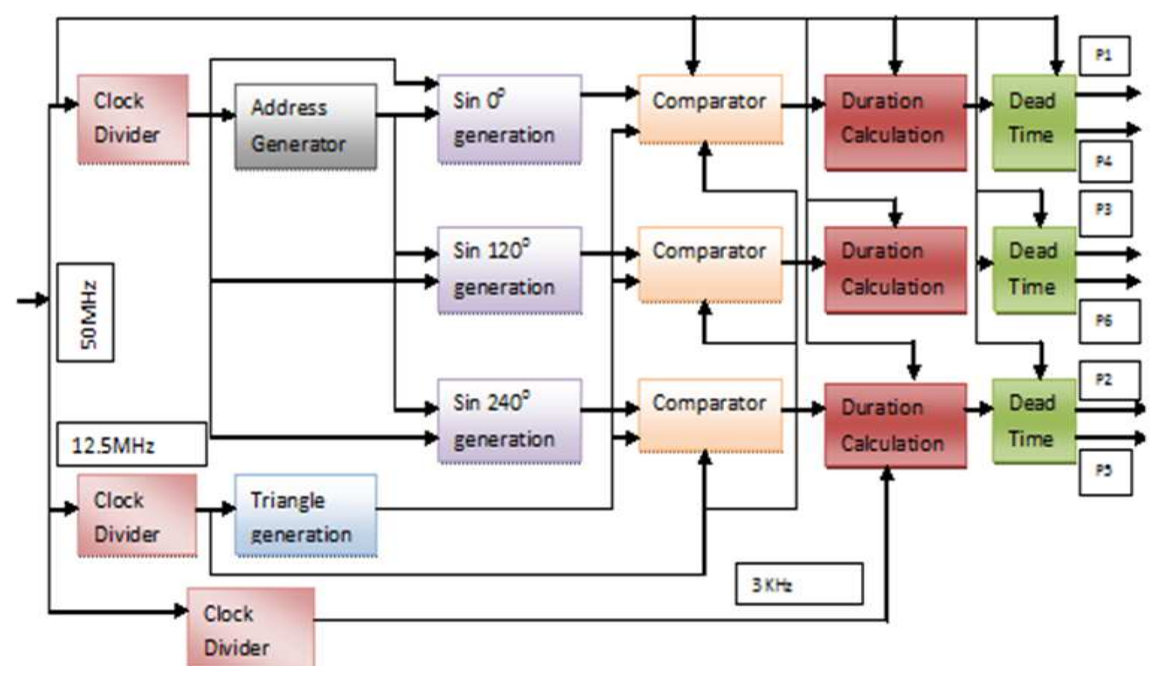

Fig. 5. FPGA implementation of the proposed scheme

Let the clock frequency be $50 \mathrm{MHz}$ which is the set frequency that the sine wave generator receives. It's quite a common thing to generate sine wave of set frequency using the governing equation given by, $\mathrm{V}(\mathrm{t})=\mathrm{Vm} \sin 2 \pi \mathrm{ft}$. But in digital logic, the problem arises in describing the limits for $t$, the time for which the wave has to be generated and the period of oscillations. Hence, the methodology we have adopted for creating the lookup table is that the instantaneous values of sinusoidal oscillations are fragmented to 200 values at equal intervals. These values are stored as an integer array named as memory.

Further instead of the factor $2 \pi \mathrm{ft}$ it is multiplied with an offset value and an integer which would in turn point to the value stored in the sine wave array. The sine array is incremented in steps of one so that to represent a half cycle of the oscillation corresponding to $360^{\circ} \mathrm{C}$, it is essential to make 199 increments of the counter. Since we are in need of three phase sine wave, we need to have three sine wave generators, whose outputs are displaced by $120^{\circ} \mathrm{C}$ each. That means, the output of the second generator must start from the initial value of zero when the first generator has swept an angle of 120 degrees. Similarly the third and second generators should follow the same fashion.

This is achieved by correlating the relation between the angular displacement and the sine array. Initially the output of first sine wave generator alone is activated and the remaining two are maintained at zero output condition. We have 360 degrees of the sine wave corresponds to 199 increments of the counter. Hence, 120 degrees of the wave would correspond to:

$$
\frac{199}{360}(120)=66
$$

Therefore, at the 66th increment of the sine array of first generator, the output of second generator is activated. Similarly, at the 66th increment of the sine counter of the second generator, the output of third one is activated. Once they are activated in this manner, then throughout the process, they are all displaced by $120^{\circ} \mathrm{C}$ or 66 counts.

\subsection{Ramp wave Generation}

The high frequency carrier chosen for comparison is of ramp in nature. This is also digitally generated. The frequency of the ramp is chosen as a high value of $5 \mathrm{kHz}$ or any value greater than this can be chosen. Unlike the sine wave, the frequency of the ramp is maintained constant. This carrier frequency would be the deciding factor of the output frequency.

\subsection{Generation of PWM}

Pulse width modulation is achieved by comparing the triangular wave and the sine wave. The instantaneous value of the sine wave is compared with the corresponding triangular wave in a comparator. The comparator provides active high output whenever the magnitude of the sine wave is greater than that of the ramp otherwise it is low.

This pulse width modulation technique is described by VHDL and simulated using modelsim environment. Since this method is flexible, an important advantage of VHDL is that it is technology independent (Lin et al., 2010). The pulses which are obtained as output is fed to the three phase bridge inverter using HDL co -simulation block.

Here a three phase inverter is controlled by SPWM, RFPWM, THI-PWM and Hybrid RF- Powergui block given in the circuit measures the fundamental voltage, THD, HSF for various values of modulation index ranging from 0.2-1.2. 


\section{RESULTS AND DISCUSSION}

Different techniques of PWM switching patterns have been implemented for improving fundamental voltage, Total Harmonic Distortion, Harmonic Spread Factor. These three factors are compared on THIPWM. The simulation model of the control circuit is shown in Fig. 6. Subsystem 1 block generates pulses for the inverter as shown in Fig. 7. SPWM, RFPWM, THIPWM, Hybrid RF-THIPWM techniques and the performance is evaluated using Modelsim and Matlab software packages.

\subsection{Fundamental Voltage and Total Harmonic Distortion}

The fundamental voltage is varied as a function of modulation index ranging from 0.2-1.2. When compared with Hybrid RF-THIPWM the fundamental component value is higher than SPWM, RFPWM and THI-PWM for the entire range of modulation index. The impact is much significant in the higher values of modulation index. The important sources of distortion in power electronic systems are: the type of modulation technique employed and the nonlinearities in the output voltage. Total Harmonic Distortion (THD) is a standard measure used to characterize the distortion in the output (Olivia et al., 2005). Figure 8 and 9 shows the proposed scheme's advantage in the variation in the fundamental and THD. Along with this linearity is retained between the fundamental voltage and modulation index.

Harmonic Spread Factor: Harmonic Spread Factor is one of the deciding factors to indicate noise generation in the motor. The harmonic spread factor can be calculated for evaluating the quality of voltage spectra of inverters using the formula:

$$
\mathrm{HSF}=\sqrt{\frac{1}{\mathrm{~N}} \sum_{\mathrm{j}=2}^{\mathrm{N}}\left(\mathrm{H}_{\mathrm{j}}-\mathrm{H}_{\mathrm{o}}\right)^{2}}
$$

Where:

$\mathrm{H}_{\mathrm{j}}=$ Value of $\mathrm{jth}$ harmonic

$\mathrm{H}_{0}=$ Average value of all $\mathrm{N}$ Harmonics

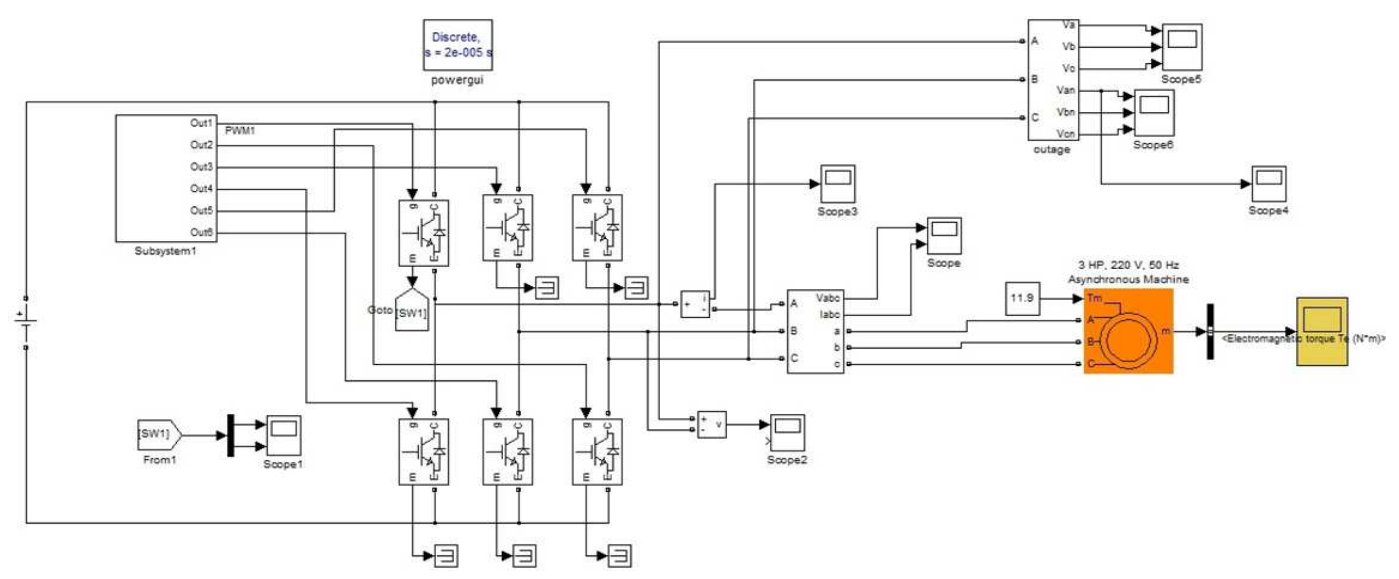

Fig. 6. Matlab Simulation model of the inverter circuit

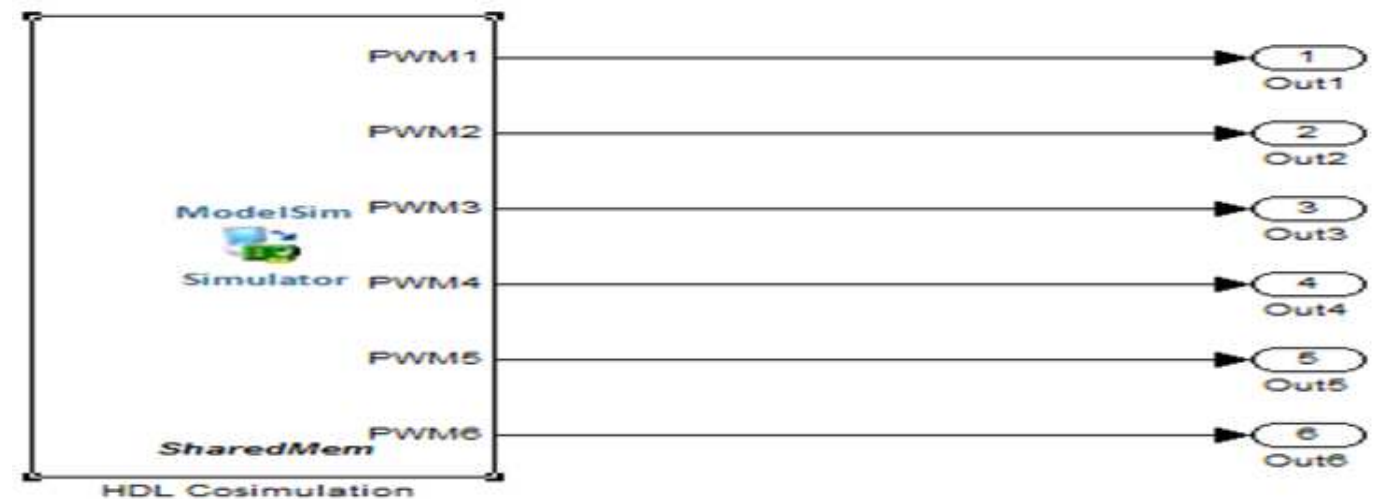

Fig. 7. MATLAb/ModelSim Co-simulation 
From Fig. 10 as the modulation index changes, the HSF also gets changed. Considering an asynchronous machine, Hybrid RF-THIPWM technique provides the lowest Harmonic Spread Factor as shown in Table 1-3 shows the improvement in fundamental voltage in Hybrid RF-THIPWM.

It can be noted that the fundamental voltage increases as the modulation index increases in all the cases. Improvement in fundamental voltage in Hybrid RFTHIPWM is more in the lower range of modulation index. In Fig. 9 THD is decreased with the increase in modulation index ranging from 0.2-1.2. RF-THIPWM shows a better performance compared to other PWM techniques. From Fig. 11-15 it is clearly understood that the THD decreases depending upon the type of PWM technique chosen and Fig. 16-20 represents the pulses obtained from modelsim using different PWM techniques.

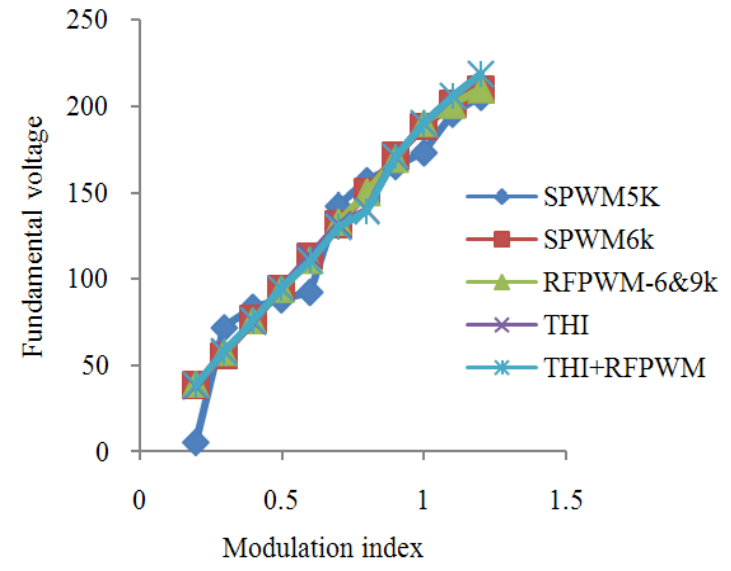

Fig. 8. Modulation index vs fundamental voltage

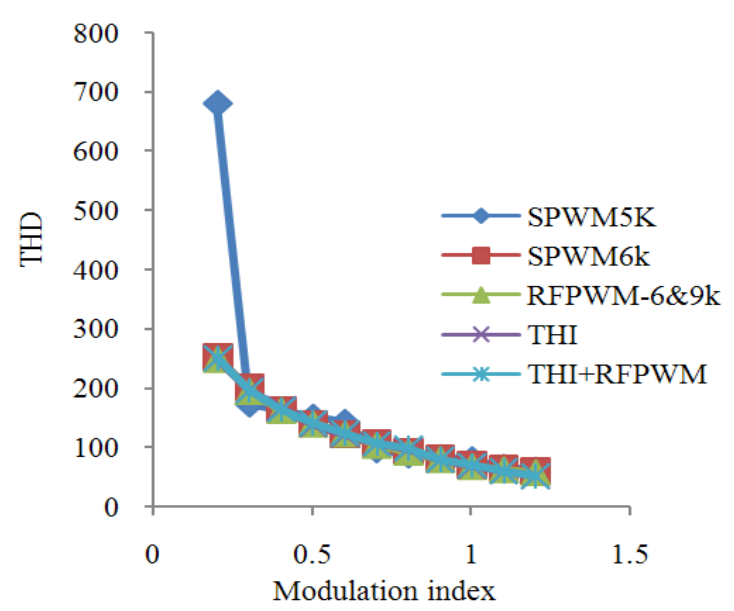

Fig. 9. Modulation Index vs THD

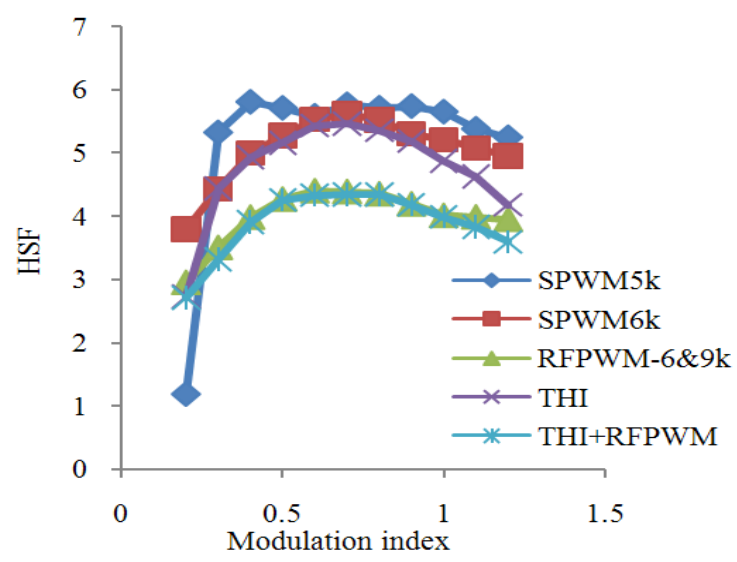

Fig. 10. Modulation index vs HSF
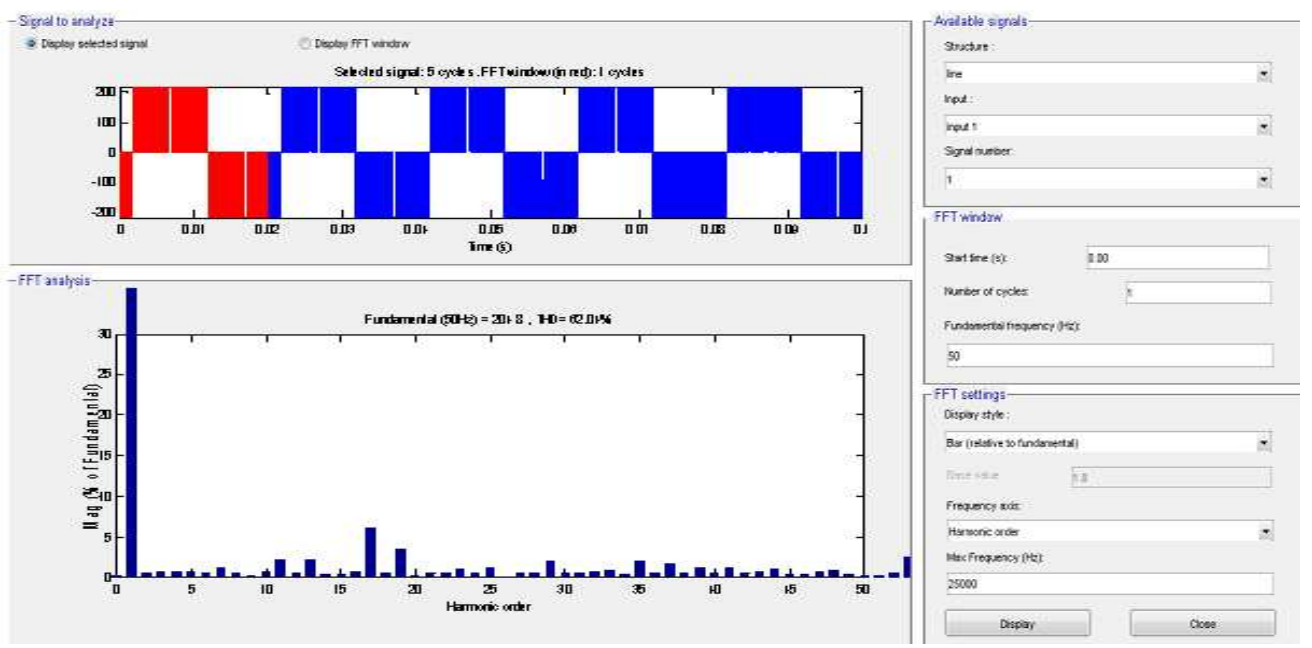

Fig. 11. FFT Analysis for M.I $=1.2$ by $\mathrm{SPWM}=5 \mathrm{KHz}$ 
Valantina Stephen et al. / American Journal of Applied Sciences 9 (11) (2012) 1802-1812

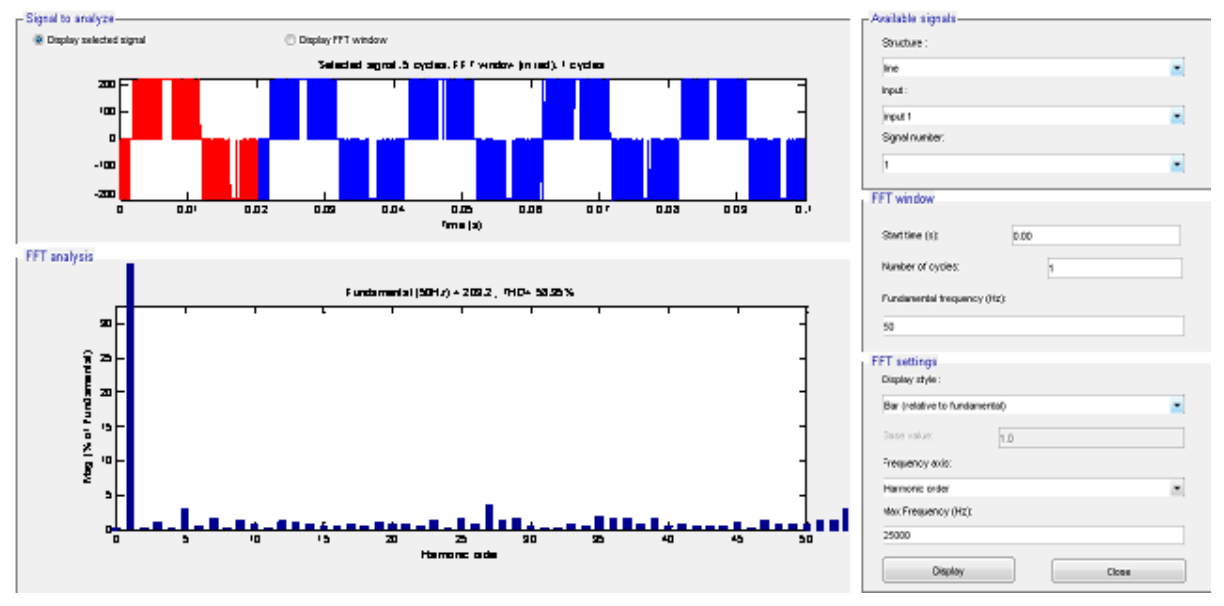

Fig. 12. FFT Analysis for M.I $=1.2$ by $\mathrm{SPWM}=6 \mathrm{KHz}$
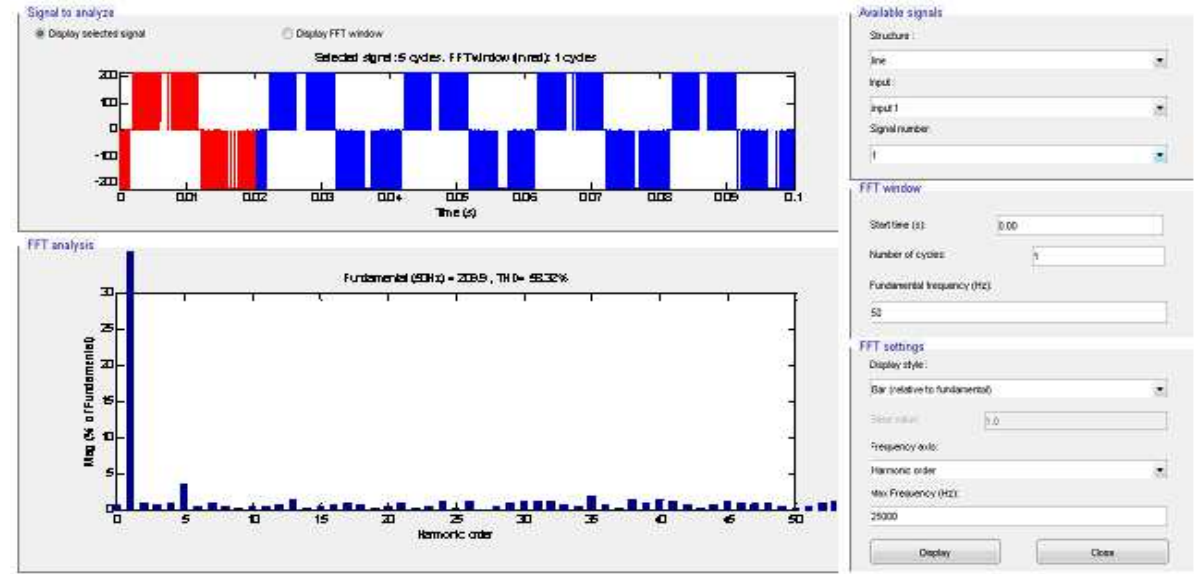

Fig. 12. FFT Analysis for M.I $=1.2$ by $\mathrm{SPWM}=6 \mathrm{KHz}$

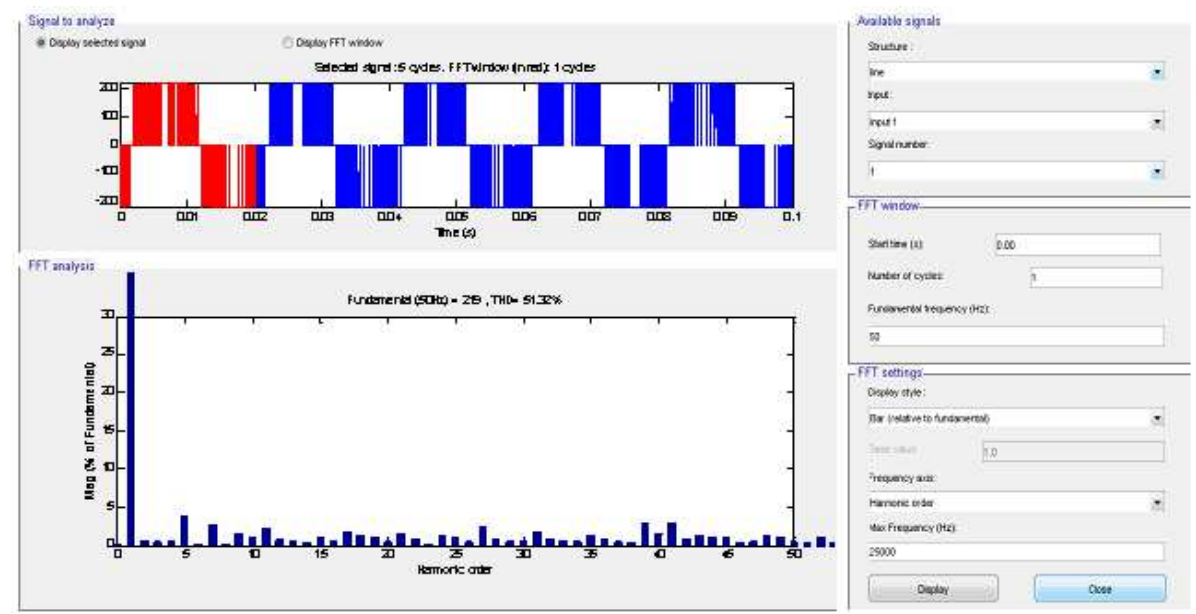

Fig. 13. FFT Analysis for M.I = 1.2 by RFPWM 
Valantina Stephen et al. / American Journal of Applied Sciences 9 (11) (2012) 1802-1812

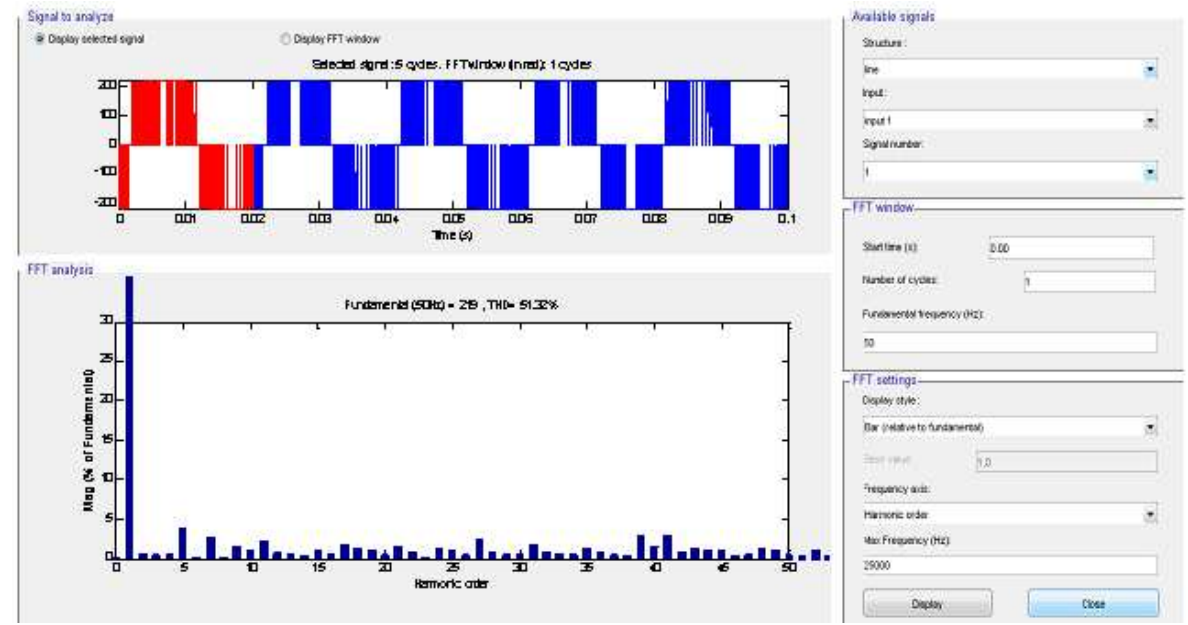

Fig. 14. FFT Analysis for M.I = 1.2 by THPWM

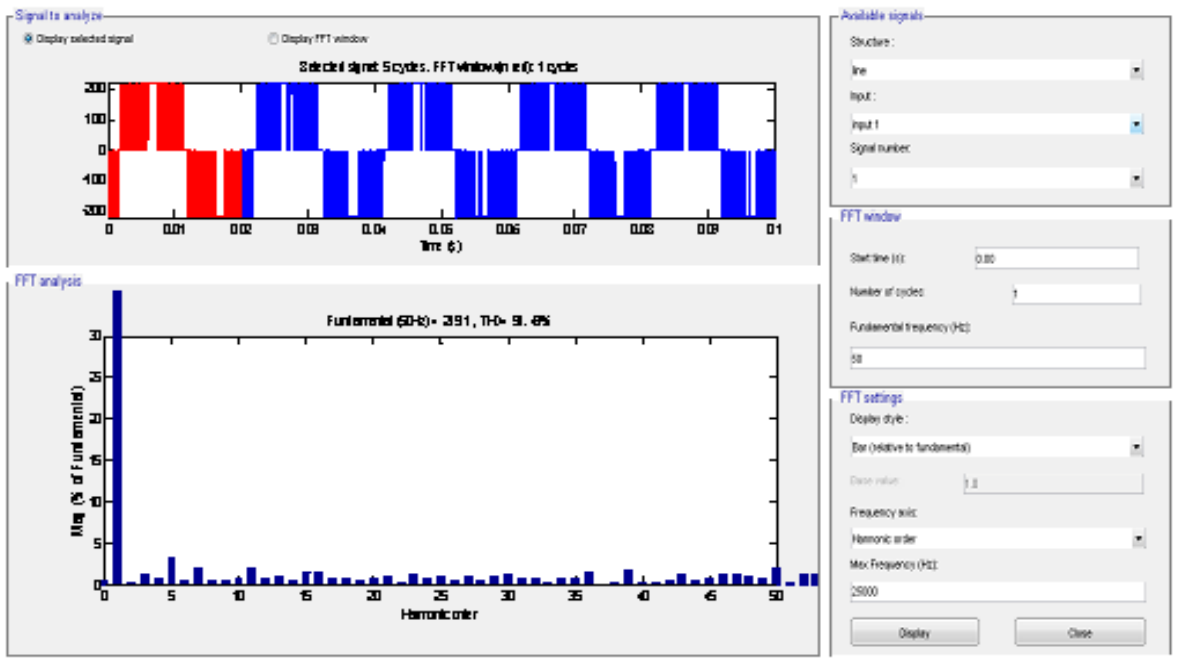

Fig. 15. FFT Analysis for M.I = 1.2 by Hybrid RF-THPWM

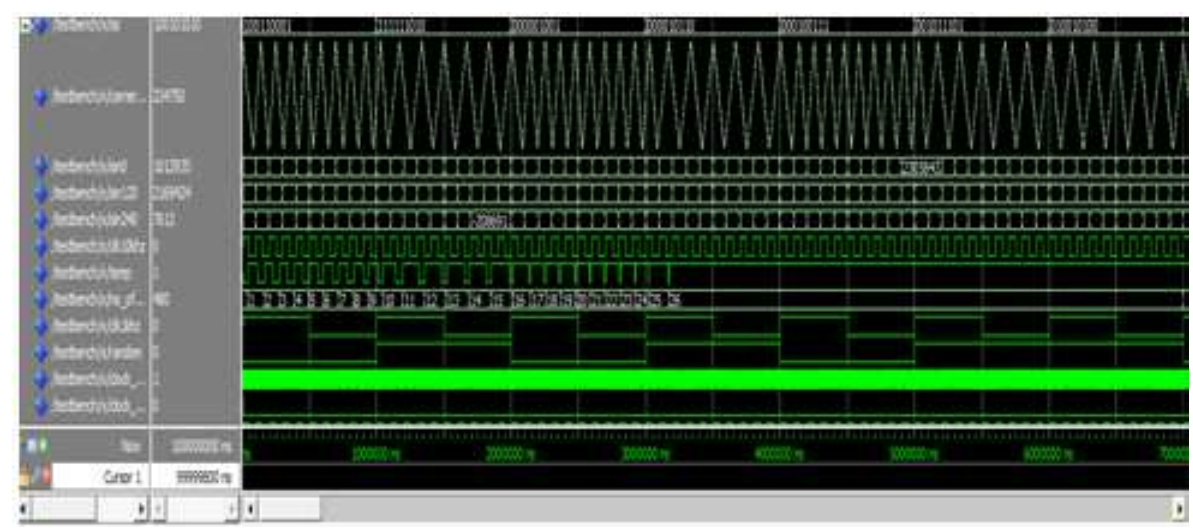

Fig. 16. Modelsim output for RFPWM with varying $f_{c}$ 


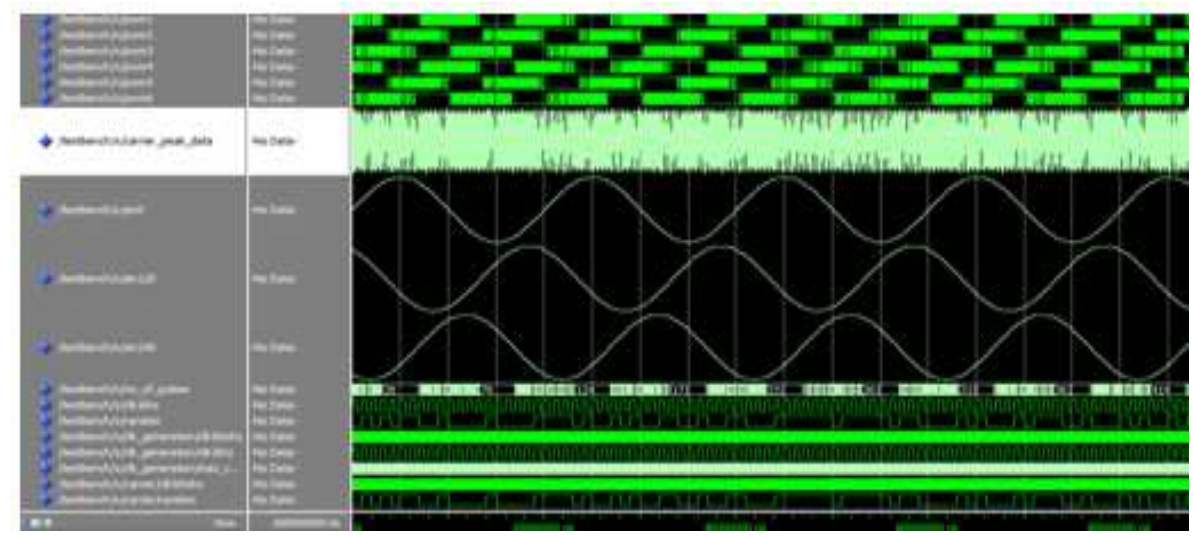

Fig. 17. Pulse output for RFPWM by modelsim

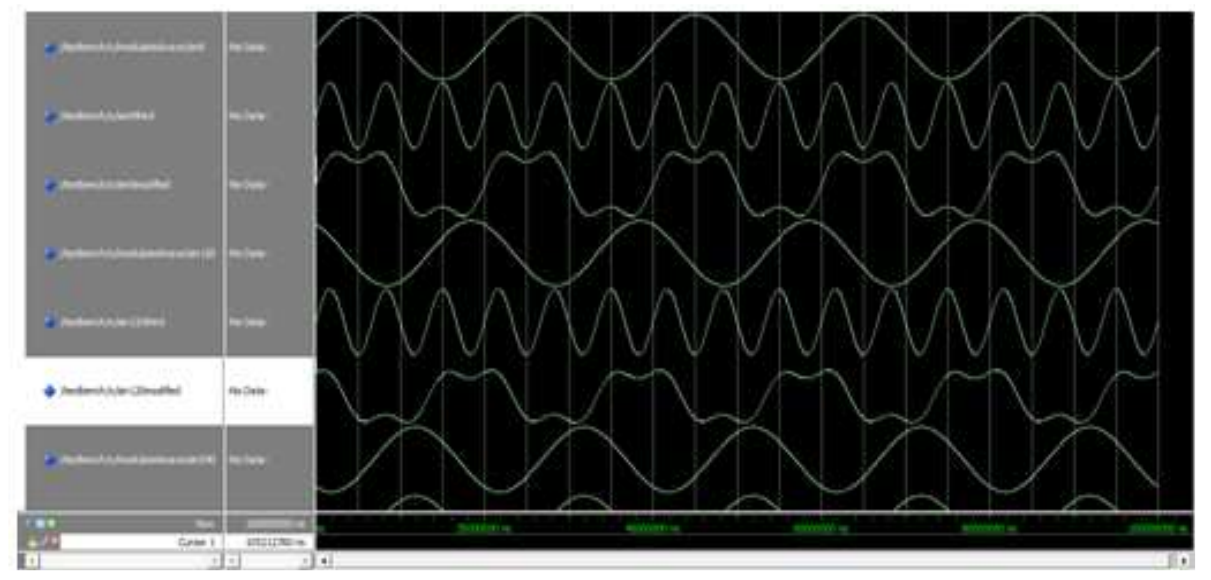

Fig. 18. Sine wave generation for THIPWM by modelsim

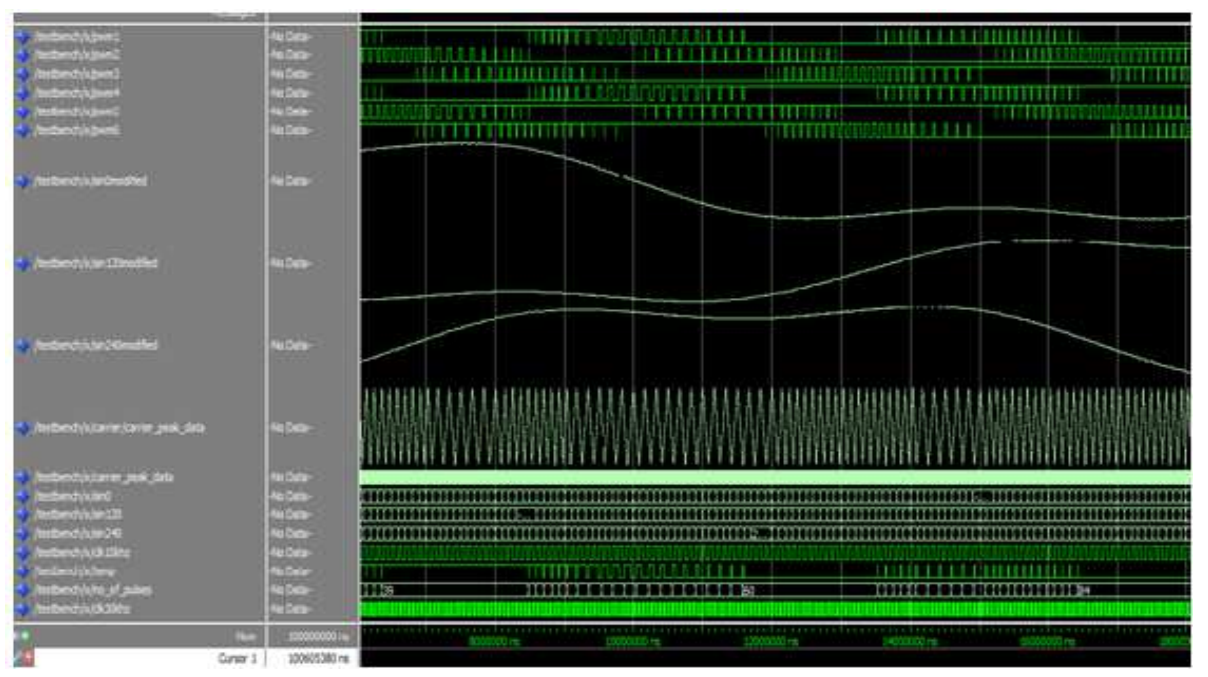

Fig. 19. Modelsim triangular waveform output for THIPWM 


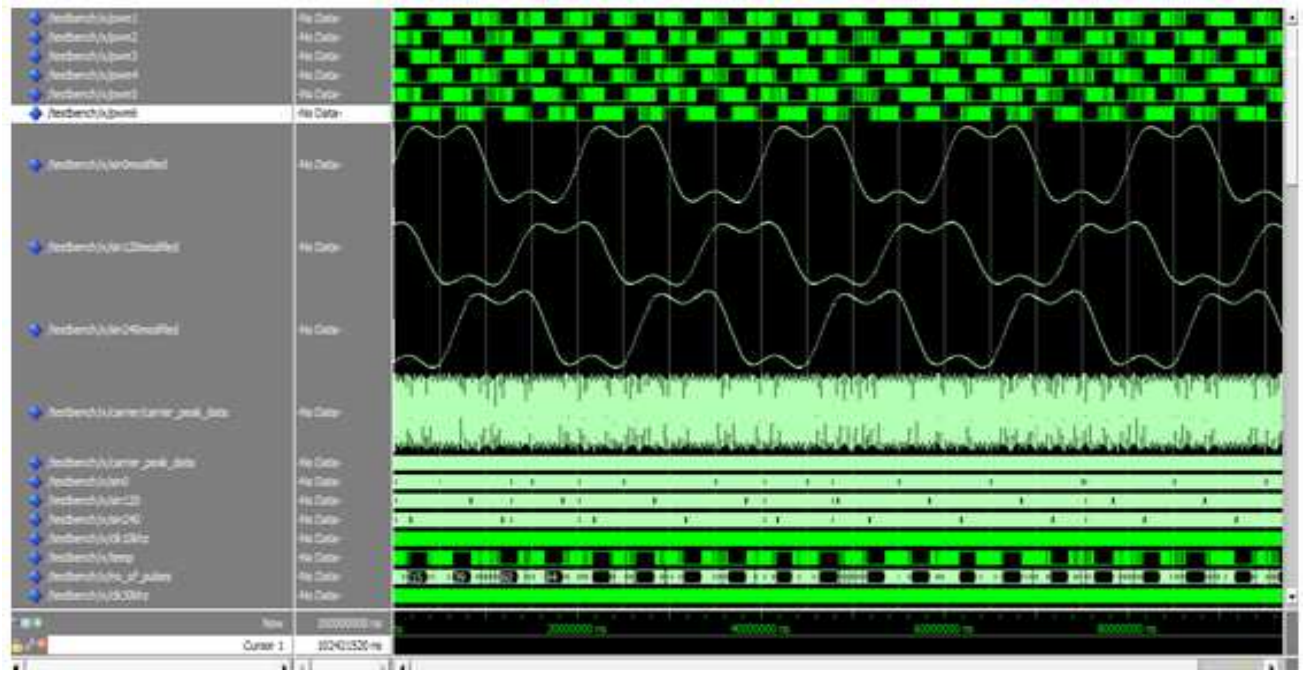

Fig. 20. Modelsim output for RF-THIPWM

Table 1. Comparison of THD and HSF for modulation index-1.2

\begin{tabular}{lrrrr}
\hline Factors & SPWM & RFPWM & THIPWM & RF-THIPWM \\
\hline THD & 252.160 & 251.7400 & 250.7900 & 249.570 \\
HSF & 3.787 & 2.9604 & 2.7269 & 2.707 \\
\hline
\end{tabular}

Table 2. Comparison of THD and HSF for modulation index-1.2

\begin{tabular}{lrrrr}
\hline Factors & \multicolumn{1}{c}{ SPWM } & RFPWM & THIPWM & RF-THIPWM \\
THD & 58.7300 & 58.0400 & 51.7400 & 50.730 \\
HSF & 4.9484 & 4.1799 & 3.9541 & 3.598 \\
\hline
\end{tabular}

Table 3. Comparison of fundamental voltage for modulation index-1.2

\begin{tabular}{llccc}
\hline Factors & SPWM & RFPWM & THIPWM & RF-THIPWM \\
\hline $\begin{array}{l}\text { Fundamental } \\
\text { voltage }\end{array}$ & 209.5 & 209.8 & 218.1 & 218.6 \\
\hline
\end{tabular}

\section{CONCLUSION}

In this study the MATLAB-ModelSim co-simulation of different types of PWM techniques are presented. The result of the proposed work shows that there is significant improvement in the fundamental voltage, THD and HSF for the given switching frequency in a three phase inverter. Obviously the simulation waveforms obtained by Matlab-Modelsim co-simulation validate the improved performance of Hybrid RF-THIPWM.

\section{REFERENCES}

Boost, M.A. and P.D. Ziogas, 1988. State-of-the-art carrier PWM techniques: A critical evaluation. IEEE Trans. Ind. Appli., 24: 271-280. DOI: $10.1109 / 28.2867$
Chang, M.Y., J.Y. Jyang, H.S. Huang, L.C. Yeh and Y.Y. Tzoul, 1997. Design and implementation of an FPGA-based control IC for the single-phase PWM inverter used in an UPS. Proceedings of the International Conference on Power Electronics and Drive Systems, May 26-29, IEEE Xpolre Press, pp: 344-349. DOI: 10.1109/PEDS.1997.618728

Chen, Y.M. and Y.M. Cheng, 1999. Modified PWM control for the DC-AC inverter with a non-constant voltage source. Proceedings of the IEEE 1999 International Conference on Power Electronics and Drive Systems, Jul. 27-29, IEEE Xplore Press, pp: 938-941. DOI: 10.1109/PEDS.1999.792833

Deepthi, J. and S.N. Saxena, 2011. Study of variation of THD in a Diode clamped multilevel inverter with respect to modulation index and control strategy. Proceedings of the International Conference and Workshop on Emerging Trends in Technology, (WETT' 11), ACM Press, New York, USA., pp: 1196-1200. DOI: 10.1145/1980022.1980284

Enjeti, P.N., P.D. Ziogas and J.F. Lindsay, 1990. Programmed PWM techniques to eliminate harmonics: A critical evaluation. IEEE Trans. Ind. Appli., 26: 302-316. DOI: 10.1109/28.54257

Farid, B. and O. Amar, 2009. A study of new techniques of controlled PWM inverters. Eur. J. Sci. Res., 32: 77-87.

Green, T.C., M. Mirkazemi, J.K. Goodfellow and B.W. Williams, 1992. Field-programmable gatearrays and semi-custom designs for sinusoidal and current-regulated PWM. Proceedings of the IEE Colloquium on ASIC Technology for Power Electronics Equipment, Feb. 20, IEEE Xplore press, London, pp: 4-4. 
Holtz, J., 1992. Pulsewidth modulation-a survey. Proceeding of the 23rd Annual IEEE Power Electronics Specialists Conference, Jun. 29-Jul. 3, IEEE Xpolre Press, Toledo, pp: 11-18. DOI: 10.1109/PESC.1992.254685

Huo, B. and M.A. Trzynadlowski, 1999. Random Pulse Width PWM Modulator for Inverter-fed Induction Motor based on the TMS320F240 DSP Controller, University of Nevada.

Hussin, H., A. Saparon, M. Muhamad and M.D. Risin, 2010. Sinusoidal Pulse Width Modulation (SPWM) design and implementation by focusing on reducing harmonic content. Proceedings of the 4th Asia International Conference on Mathematical/Analytical Modelling and Computer Simulation (AMS), May 26-28, IEEE Xplore Press, Kota Kinabalu, Malaysia, pp: 620-623. DOI: 10.1109/AMS.2010.125

Jeevananthan, S., P. Dananjayan and S. Venkatesan, 2005. A novel modified carrier PWM switching strategy for single-phase full-bridge inverter. Iran. J. Elect. Comput. Eng., 4: 101-108.

Kawamura, A., T. Haneyoshi and R.G. Hoft, 1988. Deadbeat controlled PWM inverter with parameter estimation using only voltage sensor. IEEE Trans. Power Elect., 3: 118-125. DOI:10.1109/63.4341

Kerkman, R.J., D. Leggate, B.J. Seibel and T.M. Rowan, 1996. Operation of PWM voltage source-inverters in the overmodulation region. IEEE Trans. Ind. Elect., 43: 132-141. DOI: $10.1109 / 41.481418$
Lin, F.J., J.C. Hwang, P.H. Chou and Y.C. Hung, 2010. FPGA-Based intelligent-complementary slidingmode control for PMLSM servo-drive system, IEEE Trans. Power Elect., 25: 2573-2587. DOI: 10.1109/TPEL.2010.2050907

Meco-Gutierrez, M.J., A.R. Gonzalez, F.V. Merino and J.R. Heredia-Larrubia, 2008. Reduction in induction motor heating fed by a new PWM technique: Results obtained in laboratory experiments. Universidad de Malaga.

Olivia, A., H. Chiacchiarin, A. Aymonino and P. Mandolesi, 2005. Reduction of total harmonic distortion in power inverters. Lat. Am. Applied Res., 35: 89-93.

Patel, N.D. and U.K. Madiwala, 2009. A bit-streambased PWM technique for sine-wave generation. IEEE Trans. Ind. Elect., 56: 2530-2539. DOI: 10.1109/TIE.2009.2021682

Younis, M.A.A., N.A. Rahim and S. Mekhilef, 2002. Harmonic reduction in a three-phase rectifier with sinusoidal input current. Proceedings of the International Conference on Power System Technology, (PST' 02), IEEE Xplore Press, pp: 2251-2255. DOI: 10.1109/ICPST.2002.1047184 